\title{
A Model For Effectively Assessing Student Learning Outcomes
}

\author{
Uche O. Ohia, Ph.D., Florida A\&M University, USA
}

\begin{abstract}
This paper describes a model proven to be effective for assessing and documenting evidence of student learning outcomes. Specifically, it will share a model, F.A.M.O.U.S. Copyright (02008, which is an acronym exemplifying six effective steps for complying with institutional accountability and eternal assessment requirements proscribed by the various US accreditation agencies.
\end{abstract}

Keywords: Assessment; Academic quality assurance; Institutional Effectiveness; "FAMOUS" Assessment Approach; Criteria for Success; Closing-the-Loop

\section{INTRODUCTION}

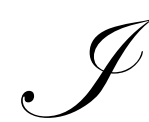

$\mathrm{n}$ higher education assessment remains an imperative in documenting evidence of institutional effectiveness and in responding to accountability demands and accreditation requirements. In particular today, assessment of institutional effectiveness (IE) is among the most important criteria for initial and re-accreditation. Palomba and Banta (1999) define assessment as "the systematic collection, review, and use of information about educational programs undertaken for the purpose of improving student learning and development" (p.4).

This paper describes a model that has been used to assess and document convincing evidence of student learning outcomes and institutional effectiveness (IE). This six-step model is an extension of Nichol's five-step model and has proven effective in assessing and documenting IE to meet the needs of self and external regulations. The six critical IE steps are easily recognizable in the acronym F.A.M.O.U.S ("FAMOUS") Approach (Copyright (O2003; (O2008 by Uche O. Ohia) which acronym exemplifies the six effective steps for improving teaching and learning as well as complying with institutional accountability and eternal assessment requirements proscribed by the various US accreditation agencies. According to Banta et al. (2009), "this new approach has led to its becoming an accepted framework for linking assessment results to planning and budgeting." (p. 19). It has been fully tested, applied and validated in one institutional setting, presented at SACS annual meeting, IUPUI Assessment Institute and constitutes the basis for the Assessment Training and Research Institute (ATaRI) convened annually as an umbrella to expose and train others to be able to effectively implement the model at their respective campuses. Most importantly the model is strongly supported by relevant literature on assessment and program evaluation. Indeed, a variety of other institutions have adapted the six steps and confirmed the model to be effective and easy to adapt and implement.

\section{LITERATURE REVIEW}

A good assessment approach simplifies and streamlines the process involved. For the most part however, institutions continue to struggle to identify effective models and the best practices for assessing and documenting effectiveness in achieving their unique missions and goals. As confirmed by Suskie (2010), "today there's a wealth of excellent resources: We now have a number of intriguing published instruments although, for many, evidence of their quality and value remains a work in progress." Among the notable documentation instruments/tools are the F.A.M.O.U.S. Assessment model, Nichols model and so on that are currently available today for the documentation of assessment activities. 
Assessment "serves three major purposes: program and service improvement, accountability to external constituencies, and progress toward institutional effectiveness to meet accrediting bodies and agencies requirements" (Ohia in Banta et al, p.84). The first purpose is aimed at making programs/units (academic majors, general education, certification programs, functional units etc.) more effective. The second purpose is aimed at demonstrating institutional responsiveness to external constituencies by ensuring that students demonstrate basic academic competencies and skills mandated by state and federal legislators. The third purpose (for institutional effectiveness) is aimed at meeting the requirements of accrediting bodies and agencies. This focus of assessment is to prove that things are done right. This requires providing evidence of what the institution/program is accomplishing and demonstrating accountability to internal and external constituent groups and stakeholders. In general, assessment can answer important questions about the learning of individual students, the effectiveness of a single course or program, or even the entire institution in general." (AAC\&U, Series p. 1)

\section{MODEL ASSESSMENT APPROACH: F.A.M.O.U.S. STEPS}

The "FAMOUS" assessment approach consists of six precise steps conceptualized to ensure that the assessment process is comprehensive, systematic, and continuous. These streamlined steps described below make it easier to tie together such processes as planning, implementation and assessment documentation that demonstrate the use of results for improvement in institutional educational outcomes and operational processes.

Step 1: Formulate statements of outcomes/objectives aligned to institutional mission/goals.

Step 2: Ascertain criteria for success.

Step 3: Measure performance using direct and indirect methods.

Step 4: Observe and analyze results for congruence between expected and actual results.

Step 5: Use results to effect improvement of programs and services.

Step 6: Strengthen programs and services by implementing an improvement action plan linked to the planning and budgeting processes.

These six "FAMOUS"steps incorporate all the key elements identified in Palomba and Banta's (1999) definition. All segments of the campus use it - from instructional programs (IP) to administrative and educational support units (ADESU), for general education and at the course level. As an innovative assessment approach, "FAMOUS" has been proclaimed as exemplary by such regulatory and professional accrediting agencies such as SACS and ABET, ACPE, ACJME and many more. A comprehensive description of each F.A.M.O.U.S. step with probing questions and examples of the type of documentation that sufficed to meet accreditation standards follows.

Step One: Formulate statements of outcomes/objectives aligned to institutional mission/goals.

\section{Probing Questions:}

1. What kinds of learning outcomes do we most value for our students and strive to help them achieve?

2. Are these outcomes/objectives derived from our institutional mission, faculty intentions in program and course design, and from knowledge of student's own goals?

Formulating outcomes (FAMOUS Step 1) is widely accepted as the first critical step in assessment. This step is addressed by two of the nine (9) American Association for Higher Education (AAHE) Principles of Good Practice for Assessing Student Learning (1996). AAHE Principle 1 states that student learning assessment should start with educational values, and Principle 3 suggests that clearly stated assessment purposes contribute to the effectiveness of assessment practices. Banta (2002) also argues that clear, explicitly stated program objectives should serve as the basis for any assessment approach. The rationale behind her argument is that stating student outcomes clearly and explicitly will contribute to the identification of appropriate methods of assessment.

"Learning Outcomes include the knowledge, skills, attitudes and habits of mind that students develop and take with them." (Suskie, 2004, p. 96) and statements of what graduates should know, be able to do, and value. (Palomba \& Banta, 2001, p. 13) 
Carefully review institutional, school/college mission/goals and formulate expected educational outcomes (knowledge, skills, and attitudes) directly tied to mission/goals statements, specific to the major discipline/department and the required general education (or core) competencies such as effective communication skills, critical thinking skills and quantitative reasoning.

Example: Statement of Program Learning Outcome

Graduates will demonstrate the ability to perform both in solo and ensemble environments. (Music Program -Professional and Career Success)

Step Two: Ascertain criteria for success.

Ascertaining Criteria for success (FAMOUS Step 2) is essential in establishing where action must be taken to improve called for at step 5. It is a trigger for "closing-the- loop" in assessment. Observed divergence between set assessment criteria and actual results holds the promise of forcing reflections on what could be done to improve the teaching and learning processes.

\section{Probing Questions:}

1. How do we know what our student's know and what they can do?

2. To what degree will students perform?

3. How do we determine progress toward intended outcomes/objectives?

Define performance expectations (standards) in terms of the percentage of students expected to pass a specific exam (e.g. licensing exams) on the first attempt, receiving at least a satisfactory score in criterion-referenced evaluations (e.g. practicum, internship) or where comparative data are available, scoring above the 50th percentile on nationally normed tests compared to their peers.

Example: Criteria for success

Direct: One hundred percent (100\%) of seniors will receive acceptable scores from a faculty jury panel using an inhouse designed rubric to evaluate their senior recital hearing.

Indirect: All the graduating students participating in an Exit Focus Group Interview will respond favorably to the interview question item "Are you comfortable with your ability to perform both in solo and ensemble environments?"

Step Three: Measure performance using direct and indirect methods.

Measuring student performance (FAMOUS Step 3) addresses the process of assessment implementation, or collection of assessment data. An important assumption embedded in this step is that multiple methods of assessment should be employed. Scholars and practitioners generally agree that learning is a complex and multidimensional process and thus suggest that assessment should use a variety of methods to maximize reliability and validity in measuring student learning and program outcomes (AAHE, 1996; Banta, 2002; Kuh, Gonyea, and Rodriguez, 2002; Palomba, 2002).

\section{Probing Questions:}

1. How do we measure the knowledge, abilities, values, attitudes, and habits of mind of our students that affect both academic success and performance beyond the classroom?

2. How do we determine progress toward intended outcomes/objectives?

Use multiple methods to measure student learning and development for a given outcome/objective. Some of the most popularly used direct measures include comprehensive final exams, capstone course/project5, and 
standardized exams such as Major Fields Test by ETS and California Critical Thinking Test. The indirect measures include employer or internship evaluations, exit survey or interviews and alumni survey. It is possible to measure several outcomes/objectives (knowledge of the discipline/subject matter, critical thinking and research skills) using one measure.

Example: Direct and Indirect Measures

Direct: A faculty jury panel using an in-house designed rubric will evaluate all graduating students performance following the senior recital hearing. All seniors will receive acceptable scores.

Indirect: $80 \%$ of graduating students participating in the Exit Focus Group Interview responded favorably to the interview question: "Are you comfortable with your ability to perform both in solo and ensemble environments?

Step Four: Observe and analyze results for congruence between expected and actual results.

Observe Results for Congruence (FAMOUS Step 4) stresses the most essential task when assessment results are in. At this step, compare the actually achieved results with the established targets or benchmarks to see if there is a gap. The identification of gaps with this step triggers corrective action at step 5 and the development and implementation of an improvement plan at step 6.

\section{Probing Questions:}

1. Do students' educational performance compare favorably with educational purposes and expectations?

2. What do students say were their experiences were with the curricula, teaching, and their own effort that led to particular outcomes?

Carefully review and summarize the results/findings for general trends. Then conduct a deeper analysis to study relationships between multiple measures of an educational outcome/objective. Through careful observation, analysis and interpretation of data, one can learn more about students' preparation for taking the next step in their careers - getting good jobs, acceptance into renowned graduate/professional schools, where one would like to see a higher level of performance and consistency in scoring at an acceptable percentile in the standardized exams as well as pointers to how strong or weak a program is.

Example: Observe results for congruence between expected and actual results.

Direct: $95 \%$ of graduating students received acceptable evaluations on their performance following the senior recital hearing.

Indirect: $90 \%$ of graduating students participating in the Exit Focus Group Interview responded favorably to the interview question: "Are you comfortable with your ability to perform both in solo and ensemble environments?"

Step Five: Use results to effect improvement of programs and services.

Using results for improvement (FAMOUS Step 5) is the core purpose of assessment because assessment results should be used continuously to improve programs and services (Banta, 2002; Hutchings, Marchese and Wright, 1991; Marchese, 1987, 1997).

\section{Probing Questions:}

1. How will the information provided be used, and by whom to guide continuous quality improvement?

At this step , popularly referred to as "Closing the loop" in assessment, the provision of evidence that demonstrates that the results of assessment have led_to the improvement of teaching/ learning processes and functional units effectiveness become of paramount importance. Therefore, reflect on assessment results and use the 
information to stimulate course and program improvements as well as institutional adjustments. Such improvements may include revisions, adjustments, additions, deletions and hiring decisions. Documented reports of efforts to improve programs based on the results of assessment are "telling indicators of a vital, ongoing assessment program". Otherwise, the assessment program needs improvement.

\section{Example:}

A reflective review of the results showed that the criterion established for the students' performance on the senior recital was not met. For this reason, the departmental faculty made a decision to require all students to perform publicly to ensure that they are prepared at the time of evaluation.

Step Six: Strengthen programs and services by implementing an improvement action plan linked to the planning and budgeting processes.

Strengthening programs and services (Step 6) together with Step 5 are at the heart of assessment because they underline the ultimate function of assessment. This is especially true when assessment is viewed from the perspective of Patton's model of utilization-focused program evaluation (1997). Kuh, Gonyea, and Rodriguez (2002) point out that it is important to strengthen feedback loops between assessment process, results, and changes in policy and practice. AAHE Principle 3 (1996) suggests that effective assessment is an ongoing process and that progress should be monitored toward intended goals and continuous improvement.

\section{Probing Questions:}

1. How is the produced evidence applied in planning, budgeting, and personnel decisions to ensure enhanced quality of education provided by the institution?

The results of assessment should inform decisions about where more resources are needed and where cutbacks would save resources to reallocate to critical program and functional areas. Such information should be considered in subsequent strategic planning exercise to justify reallocation of scarce resources. Thus link assessment data and information with the academic program's or unit's mission, strategic planning, and budgeting system. Evaluate congruence between learning outcomes and actual performance. Use assessment data to inform planning and budgeting process to ensure resource support for developing strategies for improvement of unsatisfactory outcomes. The information should justify reallocation of scarce resources - decisions about where more resources are needed and where cut-backs would save resources to reallocate to critical program and functional areas.

Example: Improvement action plan

The department will draw up an action plan to enforce the requirement that all students perform publicly to ensure that they are prepared at the time of the faculty jury evaluation of their senior recital hearing.

The goal of step six is to assure that assessment results influence planning, budgeting \& future assessment activities. It promotes continuously evaluating, planning, and allocating resources necessary to implement an action plan to ensure achieving congruence between expected and actual student learning outcomes.

\section{SUMMARY AND CONCLUSIONS}

The purpose of assessment is to improve and to provide evidence that the results have been used for decision-making and improvement of student learning outcomes. Assessment serves three major purposes that span program and service improvement, accountability to external constituencies and promoting institutional effectiveness. The F.A.M.O.U.S. assessment approach is one model that has been tested and proven effective and adaptable for implementing and documenting assessment activities systematically to meet the learning improvement needs of students and accountability to various interest groups requiring evidence of student learning outcomes, quality assurance of support services and academic programs. Each letter of the acronym, "FAMOUS", represents an important step that is connected to the next step in a chain that ultimately comes together as a cyclic and 
continuous process for effectively developing and implementing an assessment plan. FAMOUS has been widely applied as a one-size-fits-all assessment documentation approach. FAMOUS Step One (Formulate Outcomes / Objectives), and Step Two (Ascertain Criteria for Success) establish student learning or program goals/objectives as well as performance targets, benchmarks or standards. Step Three (Measure Performance) focuses attention on the important process of systematic collection of data using multiple mechanisms. Step Four (Observe Results for Congruence) involves reviewing and analyzing assessment results carefully to study variance between expected and actual results. Step Five (Use Results for Improvement) and Step Six (Strengthen Programs) emphasize the importance of using assessment information to improve educational processes and student learning outcomes through an action plan.

In general, application of the FAMOUS assessment approach ensures that the process is comprehensive, iterative, continuous, and leads to learning, teaching, support service and institutional operations improvements and quality assurance. In particular, it forces tying together assessment data and the planning and budgeting processes to promote continuous improvement.

\section{FAMOUS ASSESSMENT APPROACH}

(๐) 2003

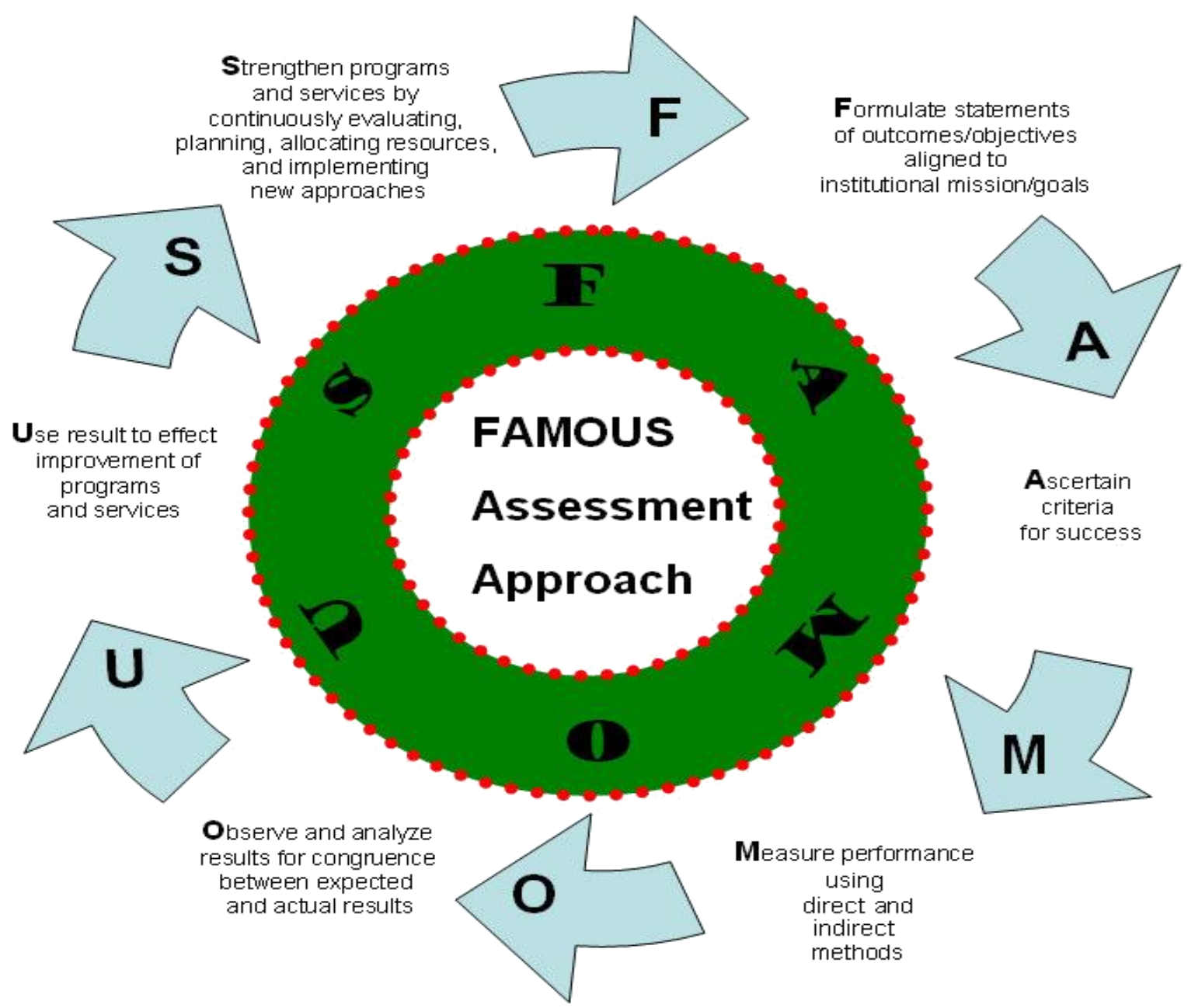




\section{AUTHOR INFORMATION}

Uche Ohia currently serves as director of university assessment at Florida Agricultural and Mechanical University. Her credentials include Ph.D./M.Ed. in Higher Education Administration from University of Pittsburgh; postgraduate diploma in Population Growth Studies from University College, Cardiff, Wales; and B. SC. degree in Mathematics/Statistics from University of Nigeria, Nsukka, Nigeria. She serves as a team evaluator for Middle States Council on Higher Education. She contributed a chapter, "Faculty ownership making a difference in a systematic General Education Assessment" in Designing Effective Assessment: Principles and Profiles of Good Practice in Assessment by Banta et.al. (2009). Notably, Uche has copyright ${ }^{2} 2008$ to F.A.M.O.U.S. assessment approach.

\section{REFERENCES}

1. AAHE (1996). 9 Principles of Good Practice for Assessing Student Learning. Retrieved December 5, 2010 from http://ultibase.rmit.edu.au/Articles/june97/ameri1.htm

2. Assessment for Institutional Effectiveness www.messiah.edu/institutional_effectiveness

3. Association of American Colleges \& Universities. Five Levels of Assessment Retrieved December 5, 2010, from http://www.aacu.org/pdf/LevelsOfAssessment.pdf

4. Banta, T.W. (Ed.) (2004). Hallmarks of Effective Outcomes Assessment. San Francisco: John Wiley \& Sons Inc.

5. Banta, T. W. (2002). Characteristics of effective outcomes assessment: Foundations and examples. In T. W. Banta (ed.) Building a scholarship of assessment. San Francisco: Jossey-Bass.

6. Dugan, R. E., \& Hernon, P. (2006). Institutional mission-centered student learning. In P. Hernon, R. E. Dugan, \& C. Schwartz (eds.), Revisiting outcomes assessment in higher education. London: Libraries Unlimited.

7. Ewell , P. T. (2008). U.S. Accreditation and the future of quality assurance: a tenth anniversary Report from the Council for Higher Education Accreditation, a CHEA Monologue Publication. http://www.insidehighered.com/news/2009/06/24/naciqi

8. F.A.M.O.U.S. Assessment Approach / FASI-Online: http://www.fasi-online.net/?id=about

9. FAMOUS Assessment Approach website: www.famousassessment.com

10. FAMOUS Approach link from Internet Resources for Higher Education Outcomes Assessment http://www2.acs.ncsu.edu/UPA/assmt/rsrc_new.htm

11. Famousassessment.com in Measuring Quality - Instruments, Products, Services, and Resources. http://applications.airweb.org/surveys/Inventory.aspx

12. FAMU Office of University Assessment webpage: $\underline{w} w w$. famu.edu/assessment

13. Hutchings, P., Marchese, T., \& Wright, B. (1991). Using assessment to strengthen general education. Washington. D. C.: American Association for Higher Education Assessment Forum.

14. Kuh, Gonyea, and Rodriguez (2002). The scholarly assessment of student development. In T. W. Banta (ed.), Building a scholarship of assessment. San Francisco: Jossey-Bass.

15. Marchese, T. J. (1987). Third down, ten years to go. AAHE Bulletin, 40, 3-8.

16. Marchese, T. J. (1997). The new conversations about learning. In Assessing impact: Evidence and actionPresentations from the 1997 AAHE Conference on Assessment and Quality. Washington, D. C.: American Association for Higher Education.

17. Middle States Commission on Higher Education (2006). Characteristics of excellence in higher education: Eligibility requirements and standards for accreditation (12th ed.). Philadelphia, PA: Author.

18. Ohia, U. O. (2009). Faculty Ownership: making a Difference in Systematic General Education Assessment. In Banta T., Jones, E. \& Black, K., Designing Effective Assessment: Principles and Profiles of Good Practices (p. 84). San Francisco: Jossey-Bass.

19. Ohia, U. O. (2009). In Banta et al., Designing Effective Assessment: Principles and Profiles of Good Practices (p. 19, 57, 84). San Francisco: Jossey-Bass.

20. Ohia, U. O. (2009). FAMOUS Assessment website: http://www.famousassessment.com/. In Banta et.al.,. Designing Effective Assessment: Principles and Profiles of Good Practices (p. 284) San Francisco: JosseyBass. 
21. Ohia, U. O. (2007)." A simplistic and integrated assessment implementation and documentation system". Paper presented at the NASPA International Assessment \& Retention Conference.

22. Ohia, U. O. (2006). "F.A.M.O.U.S.: An Innovative and Streamlined Assessment Planning and Documentation System." Paper presented at SACS Annual Meeting

23. Ohia, U. O. (2006). “A Six-step F.A.M.O.U.S. Assessment Approach.” A 75-minute workshop conducted at the IUPUI Assessment Institute in Indianapolis on Monday, October 30, 2006, from 3:45 - 5:00 p.m. at the Westin Indianapolis.

24. Palomba, C. A. (2002). Scholarly assessment of student learning in the major and general education. In T. W. Banta (Ed.), Building a scholarship of assessment. San Francisco: Jossey-Bass.

25. Palomba, C. A, and Banta, T. W. (1999). Assessment essentials: Planning, implementing, and improving assessment in higher education. San Francisco: Jossey-Bass.

26. Patton, M. Q. (1997). Utilization-focused evaluation: The new century text. ( $3^{\text {rd }}$ ed.). Thousand Oaks, California: Sage.

27. Nichols, J. O., et al. (1995). A practitioner's handbook for institutional effectiveness and student outcomes assessment implementation (3rd ed.). New York: Agathon Press.

28. Suskie, L. (2009). Assessing student learning: A common sense guide, 2nd ed. San Francisco: Jossey-Bass.

29. Suskie, Linda (2010, October 26). "Why Are We Assessing?’ Retrieved Dec 5, 2010, from http://www.insidehighered.com/views/2010/10/26/suskie 